\title{
Characterizing compositional changes of Napier grass at different stages of growth for biofuel and biobased products potential
}

\author{
Devin Takara $^{\mathrm{a}}$, Samir Kumar Khanal ${ }^{\mathrm{a}^{*}}$ \\ ${ }^{\mathrm{a} D e p a r t m e n t ~ o f ~ M o l e c u l a r ~ B i o s c i e n c e s ~ a n d ~ B i o e n g i n e e r i n g ~(M B B E) ~}$ \\ University of Hawai'i at Mānoa \\ 1955 East-West Road
}

Agricultural Science Building 218

Honolulu, HI 96822

* Author to whom all correspondences should be addressed to

Tel: +1-808-956-3812

Fax: +1-808-956-3542

E-mail: khanal@hawaii.edu 


\begin{abstract}
Napier grass, Pennisetum purpureum, is a high yielding, perennial feedstock that can be harvested year-round in (sub)tropical geographies of the world. Because of its high moisture content ( $\sim 80 \% \mathrm{w} / \mathrm{w})$, Napier grass presents a unique opportunity for fractionation into solid and liquid streams, where the extruded cellulosic fibers can serve as a substrate for biofuel production, and the nutrient-rich juice can serve as a substrate for co-product generation. The aim of this study evaluated the effects of biomass age on constituents relevant to biofuel and biobased product generation. Although obvious morphological changes can be observed in the field due to natural senescence, the results obtained in this work suggested that the cellulose content does not change significantly with respect to age. Data surrounding the hemicellulose and lignin contents, however, were inconclusive as their degree of significance varied with the statistics applied to analyze the raw data.
\end{abstract}

KEYWORDS: Biorefinery, green processing, compositional analysis, tropical grass, biofuel

\title{
1. Introduction
}

The continuous growth of global energy demands, coupled with political instability in oil-exporting countries and the persistent threat of climate change, have led to increasing concerns over the widespread use of fossil-derived resources to meet present and future needs of the people. The transportation sector in the U.S., for example, is known to occupy about $72 \%$ of the nation's total liquid fuel consumption (EIA, 2014), and still remains heavily dependent on both domestic and imported petroleum. Although recent analyses have predicted an optimistic reduction of approximately 2.1 million barrels (250 million liters) of gasoline per day over the 
next two decades, these projections are imperatively contingent on the increased penetration of biofuel and natural gas into domestic markets (EIA, 2014).

Interestingly, there are few large-scale cellulosic biofuel facilities operating in the U.S. (EMTS, 2014) which perhaps best illustrates a well-known bottleneck for commercial development: the production of biofuels cannot yet compete with petroleum-based fuels on the basis of cost. One approach to mitigate this issue has been through the establishment of biorefineries that aim to convert renewable non-food feedstocks into two or more products. In many ways, biorefineries seek to mimic the oil refineries they intend to replace, but unlike conventional oil refineries, the goods produced by biorefineries (in addition to biofuel) will vary across the country as a result of region-specific feedstocks and/or needs.

In (sub)tropical geographies of the world, year-round growing seasons offer a unique benefit for biorefineries, allowing for the continuous 12-month growth of feedstocks, and production of biofuel and biobased products. Candidate crops in these areas (i.e., herbaceous C4 grasses) grow rapidly in high yields, but also typically have higher moisture contents (> 70\%) which may complicate conventional biomass handling and logistics. An opportunity to implement innovative bioprocessing strategies like green processing, however, as proposed by Takara and Khanal (2011), exists and may be appropriate for biorefineries in these regions. Defined succinctly, green processing is the upstream fractionation of crude feedstock into solid, (hemi)cellulosic fibers for biofuel production and liquid, nutrient-rich juice for high value microbial co-product (e.g., fungal protein) production.

To enhance the economic viability of (sub)tropical biorefineries, rigorous attention must be given to the raw materials entering the processing facility. Napier grass (Pennisetum purpureum), a candidate energy crop capable of achieving high yields of 94 dry metric 
tons/hectare (Osgood et al., 1996), has been reported to have significant potential as a feedstock for large-scale renewable biofuel production in the state of Hawaii (Tran et al., 2011). Perennial feedstocks, however, are believed to change in composition over their natural course of maturation (Williams et al., 1980). In places with year-round growing seasons, there exists the potential to harvest feedstocks at ages and/or conditions which maximize both biofuel and bioproduct formation while simultaneously minimizing the overall production costs.

In this study, the structural composition of Napier grass, relevant to biofuel production, was analyzed over its natural course of maturation in the subtropical climate of Hawaii. The structural carbohydrates, lignin, ash, and extractives of the fibers were quantified and reported on a dry weight basis. Napier grass juice, collected from the green processing of crude feedstock, was characterized for its bioproduct potential based on its organic and nitrogen contents, and was reported holistically as concentrations of chemical oxygen demand (COD) and total Kjeldahl nitrogen (TKN), respectively. Insight for crop harvests was provided along with results to assist in decision making for commercial biorefineries in (sub)tropical regions of the world.

\section{Methods}

\subsection{Green processing}

Napier grass samples from Waimanalo, HI were hand collected from ratoons corresponding to 2, 4, 6, and 8 months (M) of feedstock age; the latter representing full maturity of the feedstock. The crops were continuously harvested from the same plot year-round to produce triplicate samples of the aforementioned age categories. In all cases, Napier grass was immediately transported from the field to the University of Hawaii at Manoa and was shredded by a commercial cutting mill (Vincent Corporation, Tampa, FL, USA). The moisture content of 
the raw material was determined (after shredding) by drying at $105^{\circ} \mathrm{C}$ in a convection oven until constant weight was achieved. Samples were then dewatered by screw-pressing (Vincent Corporation, Tampa, FL, USA) under 40 psi (275 kPa) of pneumatic backpressure (Takara and Khanal, 2011). Liquid juice was collected from all samples and was analyzed for TKN and COD, as described later. Extruded solid fibers were dried to a constant weight at $45^{\circ} \mathrm{C}$ and ground with a 3 hp commercial blender.

\subsection{Biomass composition}

The composition of Napier grass was determined by following a suite of Laboratory Analytical Procedures (LAPs) developed and published by the National Renewable Energy Laboratory (NREL). Detailed protocol can be found elsewhere (Sluiter and Sluiter, 2011), but in brevity, dried and ground extruded fibers were extracted by a two-stage method which first employed purified deionized water followed by 190 proof ethanol as solvents to remove the water-soluble (e.g., soil, fertilizer, miscellaneous inorganic compounds, and non-structural carbohydrates) and ethanol-soluble (e.g., waxy compounds) components of Napier grass, respectively. Samples were then air dried and digested in a two-stage sulfuric acid process (Sluiter et al., 2008a) to hydrolyze hemicellulose and cellulose into their monomeric backbone sugars; xylose and glucose, respectively. Monosaccharides were elucidated and quantified by high performance liquid chromatography (HPLC) with methods described later. Other minor sugars, namely arabinose, were also known to be present, but their concentrations were minimal and among the lower limits of detection (and baseline noise) using a refractive index detector. The concentrations of minor sugars were not reported in the final mass closure of Napier grass as their values were too low and inconsistently integrated. Ash and lignin were determined by 
gravimetric and spectrophotometric analyses (Sluiter et al., 2008a; Sluiter et al., 2008b). Samples were run concurrently with a bagasse standard (\#8491) purchased from the National Institute of Technology and Standards (NIST).

\subsection{Juice characteristics}

Liquid analyses of juice collected during green processing were conducted as per protocols described by commercial TKN and COD test kits (HACH, Loveland, CO, USA). The instrumentations used included a HACH Digesdahl apparatus, HACH DRB 200 heater and HACH DR 5000 UV-spectrophotometer (HACH, Loveland, CO, USA). The nitrogen and organic content of Napier grass juice, measured as TKN and COD, respectively, are known to be essential characteristics for promoting and enhancing high value fungal co-product generation from biorefinery processes (Nitayavardhana et al., 2013). TKN and COD were used as general parameters to describe the potential to produce alternative (high value) products for increased revenue generation in subtropical regions.

\subsection{Carbohydrate analyses}

Aliquots of $5 \mathrm{~mL}$ were taken from the hydrolysates produced by the two-stage acid digestion of Napier grass samples, and were neutralized to a pH of 5 with calcium carbonate (Sluiter, 2008a). The samples were centrifuged at 12,857g, corresponding to 10,000 rpm (F-346-38 Eppendorf, Hauppage, NY, USA), for $10 \mathrm{~min}$ at room temperature. The supernatants (1 $\mathrm{mL}$ ) were passed through a $0.2 \mu \mathrm{m}$ nylon syringe filter into glass vials, and were automatically injected into a Waters 2695 separations module equipped with a Waters 2416 refractive index detector (Waters, Milford, MA, USA) and Rezex RPM Monosaccharide column (Phenomenex, 
Torrance, CA, USA). The system was run at $0.6 \mathrm{~mL} / \mathrm{min}$ and $85^{\circ} \mathrm{C}$ maintained by an external column heater (Waters, Milford, MA, USA). Standard solutions were made and injected periodically to verify the calibration and integrity of the system as per NREL protocols (Sluiter et al., 2008a).

\subsection{Statistical analyses}

The mean values for biomass constituents were compared by an analysis of variance (ANOVA) with statistical software (Statistical Product and Service Solutions (SPSS) v.17, IBM, Chicago IL, USA). Replicate harvests were blocked to account for uncontrolled (natural) variations occurring within each age category. Statistically significant differences in composition, determined at $\alpha \leq 0.05$, were further elucidated by a Duncan's and Tukey's comparison. Moisture content data were also compared by a post-hoc Tukey’s comparison using SPSS. All results were reported with their corresponding confidence intervals when significant.

\section{Results and discussion}

\subsection{Moisture content for green processing}

The initial moisture content of raw Napier grass was found to correlate with biomass age, as shown in Figure 1(a). More specifically, 2M and 6M old crops were found to have higher moisture contents than 4M and 8M old crops $(\mathrm{p}<0.01)$. The extruded fiber for all age categories, however, maintained a relatively stable average moisture content of approximately 55-60\% after screw-pressing. An explanation describing the significant increase in the initial moisture content of raw Napier grass observed between the ages of 4M and 6M remains elusive, see Figure 1(a). Cumulative precipitation data from the field (Figure 1(b)) were not found to 
correlate with any of the observed moisture contents. Although the effects were not measured in this study, the varying leaf-to-stalk ratio of the Napier grass as it matured in the field may have influenced water loss via transpiration (Eavis and Taylor, 1979), and could perhaps explain the observed moisture changes.

\section{Figure 1}

\subsection{Extractives content}

An ANOVA with respect to feedstock maturity suggested that no statistically significant correlation existed between the Napier grass extractives content and biomass age at the time of harvest ( $p=0.99)$; data not shown. The extractives content, while important for complete mass closures, represents a collection of water and ethanol soluble components that are generally not suitable or of interest for biofuel and biobased product generation.

\subsection{Carbohydrate content}

Structural carbohydrates comprise the largest fraction of all lignocellulosic feedstocks ( $\sim 60 \%)$ on a dry weight basis and serve as the precursor for biofuel production as well as various other biobased products (FitzPatrick et al., 2010). Quantification of (hemi)cellulose is essential for defining the theoretical limits used for determining pretreatment and saccharification efficiencies. Presently, only a few studies have considered the effects of feedstock maturity on the compositions of candidate biofuel crops (Waramit et al., 2011), and not much is known about the biorefining potential in (sub)tropical geographies which experience minimal seasonal changes year-round. The physical changes of Napier grass observed in the field during maturation (e.g., increasing woodiness of the stalks and drying of leaves) suggests that biochemical changes in the plant may also occur. A similar observation has been made for other 
perennial grasses as previously reported by Williams et al. (1980).

Interestingly, statistical analyses of the data by ANOVA illustrated that there were no significant differences between the ages for cellulose ( $\mathrm{p}=0.24)$. In contrast, hemicellulose was found to vary slightly ( $\mathrm{p}=0.04$ ), but a post-hoc Tukey's comparison was inconclusive. Younger Napier grass (i.e., 2 months old) contained less hemicellulose (reported as xylan) on a dry weight basis, but was not found to differ statistically from more mature Napier grass using a Tukey's comparison at $\alpha=0.05$. Thus, the total structural carbohydrate content of Napier grass remains relatively constant and predictable across the different ages. A Duncan's range test, which can sometimes bias Type I errors, was in agreement with the results determined by the Tukey's test.

\subsection{Lignin content}

\section{Table 1}

Examination of lignin with respect to Napier grass growth generated interesting results. The lignin content of the replicate harvests was found to vary within each age group, and it appeared that lignin may have increased after successive ratoons. Additionally, with respect to age, the lignin content also appeared to increase as the feedstock matured in the field $(\mathrm{p}=0.03)$; but similar to hemicellulose, the observed increase in lignin on a dry weight basis was inconclusively resolved using a Tukey's comparison test at $\alpha=0.05$. A Duncan's range test, however, indicated that the lignin in 2 month old Napier grass was significantly less than older samples at $\alpha=0.05$. Data and field observations suggest that lignin may be influenced by a combination of age as well as environmental changes/stressors (Cipollini, 1997; Buxton and Russell, 1988), however, more research is required to validate such relationships.

\subsection{Ash content}

The dry weight ash content of Napier grass was found to vary with age, and is consistent 
with other studies (Yoshida et al., 2008). Specifically, younger Napier grass was found to contain significantly higher quantities of ash than older material as determined by a Duncan’s range test. As in the case with xylan and lignin, a Tukey’s comparison of ash did not resolve statistical differences between the age groups. It is important to note that unlike the Duncan's range test, a Tukey’s comparison may sometimes be prone to bias Type II errors (i.e., false negatives). The strongest conclusions can be made about statistical significance between a group of means when the two tests (namely, Duncan and Tukey) are in agreement. From previous studies, ash is known to occur in higher quantities in young Napier grass as a result of passive and active mechanisms for self defense in grasses belonging to the Poaceae family (Motomura et al., 2004). The compositional characteristics of the feedstock are summarized in Table 1.

\subsection{Total Kjeldahl nitrogen (TKN) and chemical oxygen demand (COD)}

Napier grass juice was collected after a dewatering process described elsewhere (Takara and Khanal, 2011). As mentioned previously, the juice may have implications in other bioprocessing operations within a biorefinery, but because co-product generation was outside the scope of the current study, only basic measurements of the nitrogen content, determined as TKN, were quantified. The results are reported in Figure 2(a) on a g TKN/g biomass basis.

Statistical analyses of the TKN data by both a Duncan and Tukey’s comparison test indicated that there were no significant differences in the concentration of nitrogen found in Napier grass juice with respect to feedstock age. It is important to note, however, that the volume of juice recovered from mature feedstock (i.e., 8 months old) was much less than that recovered from 2 month old material; namely, $1.8 \mathrm{~L}$ of juice compared to $3.3 \mathrm{~L}$ from $5 \mathrm{~kg}$ fresh feedstock, respectively. 
The organic content of Napier grass juice was quantified and reported holistically as COD; a parameter known to be valuable for high value co-product generation like protein-rich fungal biomass (Nitayavardhana and Khanal, 2010; van Leeuwen et al. 2012; Nitayavardhana et al., 2013). Microbial cultures are able to utilize the organic constituents in liquid substrates, consequently reducing COD concentrations while simultaneously producing microbial biomass and/or high value biobased products.

\section{Figure 2}

Figure 2(b) illustrates the results of COD analyses with respect to feedstock age. The COD concentrations found in Napier grass juice were $20 \%$ lower than the values reported by Nitayavardhana and Khanal (2010) for sugarcane vinasse. Although this serves to suggest that the juice is less of an environmental concern, the lower concentrations of COD may also result in less potential for high value co-products. Statistical comparisons of the acquired data by Duncan and Tukey approaches show that the COD concentration of juice is also irrespective of feedstock maturity. For the TKN and COD samples presented, there was a high degree of variability observed for each harvest. The nitrogen content was initially thought to correspond with fertilization which occurred at the start of the experiment, however, no significant decrease overall in TKN was observed as the plant senesced. More information is required to determine whether the source of the observed variability in the COD and TKN data is the result of natural causes or by some other factor.

\section{Conclusions}

The structural carbohydrates of Napier grass were not found to vary conclusively with respect to age. Juice recovered contained highly variable concentrations of TKN and COD, and requires 
further analyses to determine its applicability for co-product generation. The implications of this study suggest that it is impossible to recommend an optimal age for harvest on the basis of biomass age and composition alone. Because of the relative predictability of feedstock constituents, dry matter data in conjunction with a representative compositional analysis may prove to be the most insightful for evaluating biorefining potential and the commercial viability of herbaceous biomass-to-biofuel technologies.

\section{Acknowledgements}

This work was supported by the U.S. Department of Energy (USDOE), award no. DE-FG3608G088037 and Biomass Research and Development Initiative (BRDI), grant no. 2012-1000619455. The authors would also like to thank Dr. Richard Ogoshi for his assistance in field work, as well as Dr. Scott Turn for his kind support in feedstock preprocessing operations.

\section{References}

1. Buxton, D. R., Russell, J. R., 1988. Lignin constituents and cell-wall digestibility of grass and legume stems. Crop Sci. 28, 553-558.

2. Cipollini Jr., D. F., 1997. Wind-induced mechanical stimulation increases pest resistance in common bean. Oecologia 111, 84-90.

3. Eavis, B. W., Taylor, H. M., 1979. Transpiration of soybeans as related to leaf area, root length, and soil water content. Agron. J. 71, 441-445.

4. EMTS 2014 Data. 2014. U.S. Environmental Protection Agency (US EPA). Available from http://www.epa.gov/otaq/fuels/rfsdata/2014emts.htm. 
5. FitzPatrick, M., Champagne, P., Cunningham, M. F., Whitney, R. A., 2010. A biorefinery processing perspective: Treatment of lignocellulosic materials for the production of value-added products. Bioresour. Technol. 101, 8915-8922.

6. Nitayavardhana, S., Issarapayup, K., Pavasant, P., Khanal, S. K., 2013. Production of protein-rich fungal biomass in an airlift bioreactor using vinasse as substrate. Bioresour. Technol. 133, 301-306.

7. Nitayavardhana, S., Khanal, S. K., 2010. Innovative biorefinery concept for sugar-based ethanol industries: Production of protein-rich fungal biomass on vinasse as an aquaculture feed ingredient. Bioresour. Technol. 101, 9078-9085.

8. Motomura, H, Fujii, T., Suzuki, M., 2004. Silica deposition in relation to ageing of leaf tissues in Sasa veitchii (Carriere) Rehder (Poaceae: Bambusoideae). Ann. Bot. 93, 235248.

9. Osgood, R., Dudley, N. S., Jakeway, L. A., 1996. A demonstration of grass biomass production on Molokai.

10. Sluiter, A., Hames, B., Ruiz, R., Scarlata, C., Sluiter, J., Templeton, D., Crocker, D. 2008a. Determination of structural carbohydrates and lignin in biomass, National Renewable Energy Laboratory.

11. Sluiter, A., Hames, B., Ruiz, R., Scarlata, C., Sluiter, J., Templeton, D., 2008b.

Determination of ash in biomass, National Renewable Energy Laboratory.

12. Sluiter, J., Sluiter, A. 2011. Summative mass closure, National Renewable Energy Laboratory. 
13. Takara, D., Khanal, S. K., 2011. Green processing of tropical Napier grass into biofuel and biobased products: An innovative biorefinery approach. Bioresour. Technol. 102, $1587-1592$.

14. Tran, N., Illukpitiya, P., Yanagida, J. F., Ogoshi, R., 2011. Optimizing biofuel production: An economic analysis for selected biofuel feedstock production in Hawaii. Biomass Bioenerg. 35, 1756-1764.

15. U.S. Energy Information Administration (EIA), 2014. International Energy Outlook. Available from http://www.eia.gov/forecasts/ieo/pdf/0484(2014).pdf.

16. van Leeuwen, J., Rasmussen, M. L., Sankaran, S., Koza, C. R., Erickson, D. T., Mitra, D., Jin, B., 2012. Fungal treatment of crop processing wastewaters with value-added coproducts sustainable bioenergy and bioproducts, in: K. Gopalakrishnan, van Leeuwen, J., and Brown, R. C. (Eds.), Sustainable Bioenergy and Bioproducts: Value Added Engineering Applications. Springer, London, pp. 13-44.

17. Waramit, N., Moore, K. J., Heggenstaller, A. H., 2011. Composition of native warmseason grasses for bioenergy production in response to nitrogen fertilization rate and harvest date. Agron. J., 103, 655-662

18. Williams, T. E., Osbourn, D. F., Murdoch, J. C., Nix, J. S., Craven, J., Kilkenny, J. B., 1980. Grass: Its production and utilization, in: Holmes, W. (Ed.), Grass: Its Production and Utilization. Blackwell Scientific, Missouri, pp.73.

19. Yoshida, T., Turn, S. Q., Yost, R. S., Antal Jr., M. J., 2008. Banagrass vs Eucalyptus wood as feedstocks for metallurgical biocarbon production. Ind. Eng. Chem. Res. 47, 9882-9888. 


\section{TABLE CAPTIONS}

Table 1. Composition of Napier grass with respect to age, $(n=3)$.

\section{FIGURE CAPTIONS}

Figure 1. (a) Moisture content of raw Napier grass with respect to age at harvest; (b) Cumulative precipitation data collected at the Waimanalo Experiment Station.

Figure 2. (a) TKN concentration of Napier grass juice with respect to age, (n=3); (b) COD concentration of Napier grass juice with respect to age, $(n=3)$. 
Table 1

\begin{tabular}{|c|c|c|c|c|c|c|}
\hline Sample & $\begin{array}{c}\mathbf{\%} \\
\text { Glucan }\end{array}$ & $\begin{array}{c}\text { \% } \\
\text { Xylan }\end{array}$ & $\begin{array}{c}\mathbf{\%} \\
\text { Lignin }\end{array}$ & $\begin{array}{c}\text { \% } \\
\text { Extractives }\end{array}$ & $\begin{array}{c}\text { \% } \\
\text { Ash }\end{array}$ & $\begin{array}{c}\text { \% } \\
\text { Total }\end{array}$ \\
\hline NIST & $41.9 \pm 0.9$ & $22.9 \pm 0.6$ & $25.4 \pm 0.2$ & $4.7 \pm 1.4$ & $3.4 \pm 0.5$ & 98.3 \\
\hline $\mathbf{2 M}$ & $35.0 \pm 2.9$ & $19.2 \pm 1.2$ & $15.3 \pm 3.4$ & $14.6 \pm 1.6$ & $15.3 \pm 1.8$ & 99.3 \\
\hline $\mathbf{4 M}$ & $38.5 \pm 2.3$ & $22.8 \pm 2.2$ & $17.9 \pm 1.6$ & $14.3 \pm 1.8$ & $8.8 \pm 3.3$ & 102.4 \\
\hline $\mathbf{6 M}$ & $38.6 \pm 3.6$ & $23.4 \pm 1.3$ & $17.5 \pm 2.7$ & $14.4 \pm 1.7$ & $10.6 \pm 2.3$ & 104.5 \\
\hline $\mathbf{8 M}$ & $39.4 \pm 2.2$ & $21.7 \pm 1.0$ & $18.3 \pm 2.2$ & $14.8 \pm 2.3$ & $8.7 \pm 0.7$ & 102.9 \\
\hline
\end{tabular}

* NIST = National Institute of Standards and Technology bagasse standard \#8491; M = Month

Figure 1

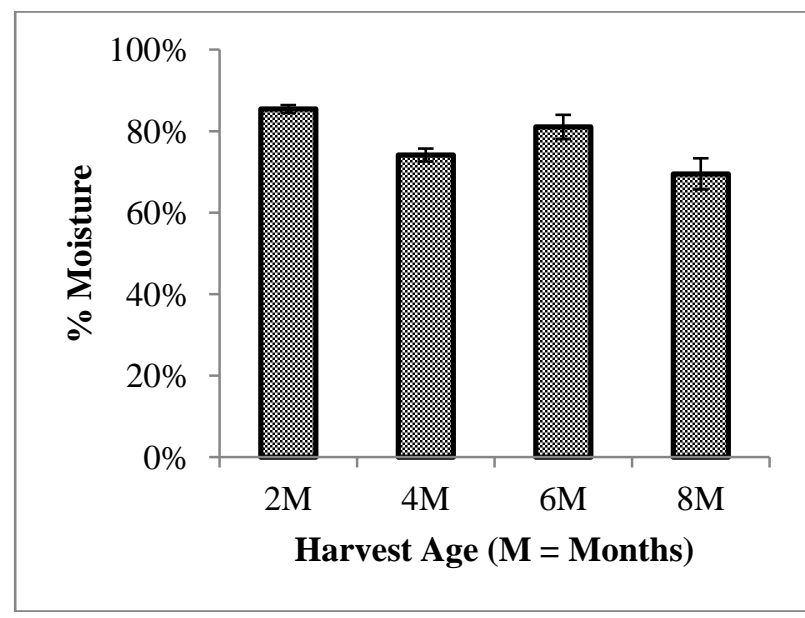

(a)

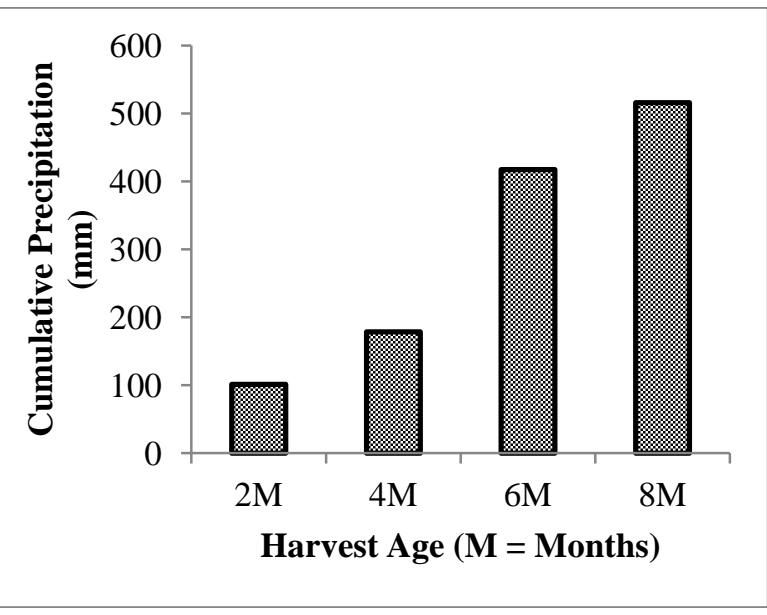

(b)

\section{Figure 2}

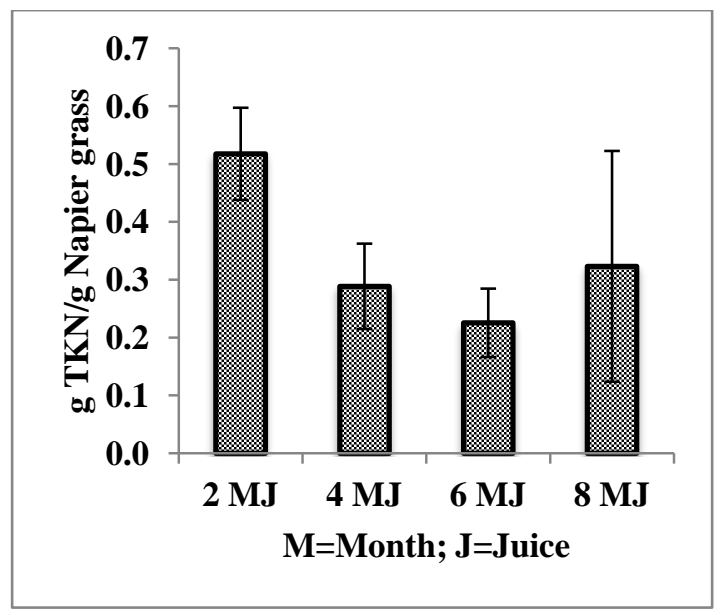

(a)

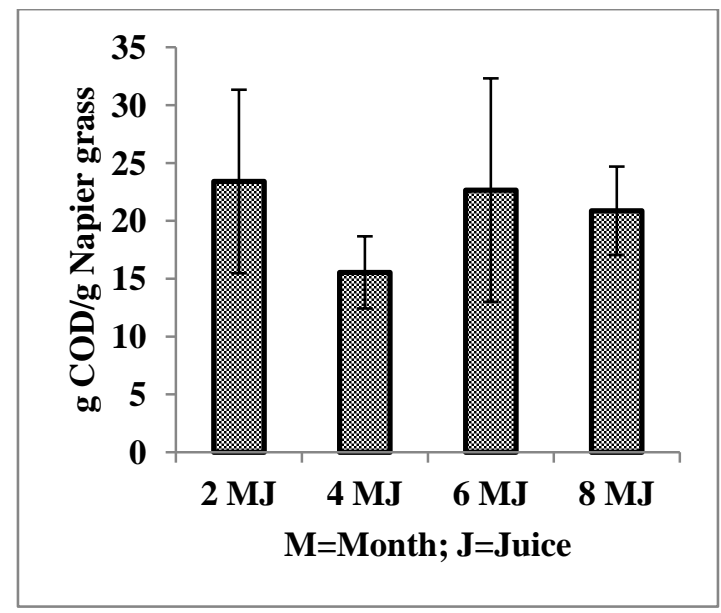

(b) 